\title{
Clinical Reasoning: A 30-year-old man with headache and sleep disturbance
}

Stephen W. English, MD, B. Mark Keegan, MD, Eoin P. Flanagan, MB, BCh, W. Oliver Tobin, MB, BCh, BAO, PhD, and Nicholas L. Zalewski, MD

Neurology ${ }^{\circledR}$ 2018;90:e1535-e1540. doi:10.1212/WNL.0000000000005356

\section{Section 1}

A 30-year-old man with a history of migraine presented to the emergency department with headache and somnolence. Previous migraine headaches were infrequent and episodic, typically lasting less than 1 day, while the current headache had been building over the course of 2 months and was accompanied by fluctuating hypersomnolence and insomnia. On the day of admission, he was confused, dysarthric, somnolent, and unable to ambulate without assistance. A thorough review of collateral history revealed a remote travel history throughout Asia, Europe, Africa, and Mexico, but no clear infectious exposures. He smoked marijuana but denied exposure to illicit drugs. Family history included hypothyroidism in his mother and psoriasis in his sister. Upon arrival to the emergency department, he was afebrile and hemodynamically stable. Neurologic examination did not reveal a focal deficit or clear evidence of papilledema on funduscopy, but cooperation was poor due to level of consciousness.

An emergent head CT scan revealed obstructive hydrocephalus due to an apparent diencephalic mass (figure, A). External ventricular drain placement led to rapid improvement in level of consciousness, and the patient was admitted for additional evaluation. Brain MRI following admission demonstrated a large, avidly enhancing diencephalic lesion (figure, B and C).

\section{Questions for consideration:}

1. What are common clinical signs and symptoms of acute hydrocephalus?

2. What is the differential diagnosis based on the clinical presentation and imaging?
Correspondence

Dr. English

English.stephen@mayo.edu

GO TO SECTION 2 
Figure Diencephalic mass lesion secondary to anti-Ma-2-associated encephalitis presenting as obstructive hydrocephalus
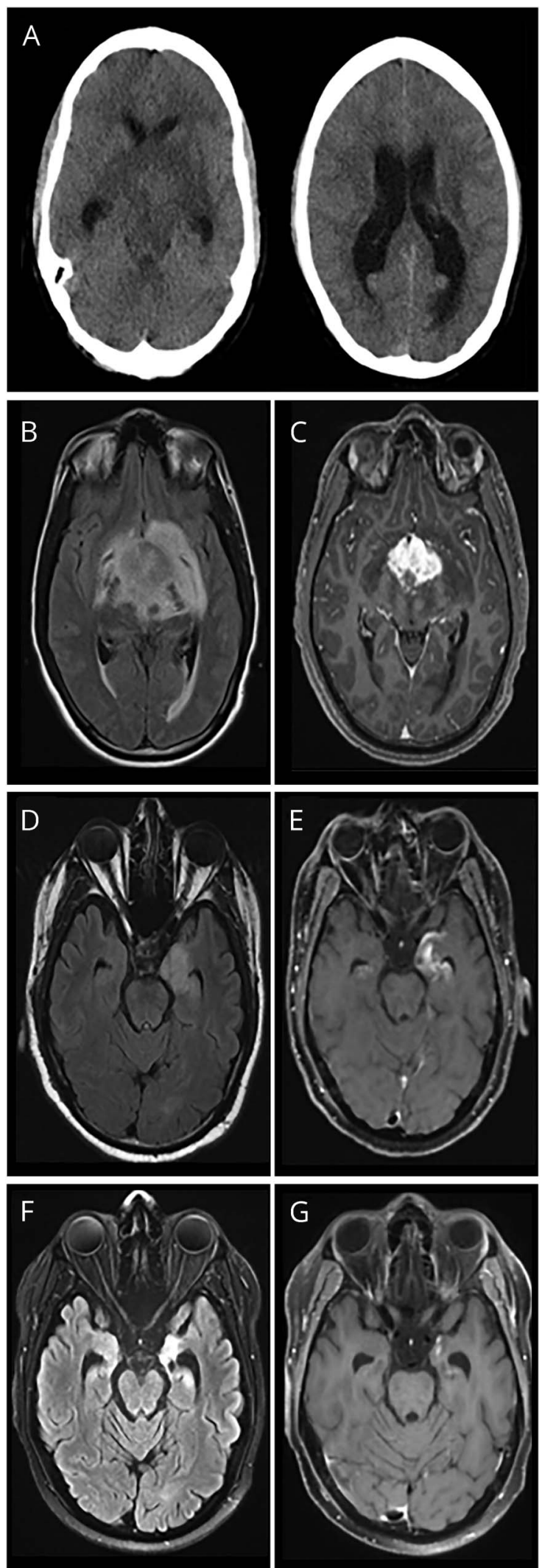

(A) CT head obtained upon presentation demonstrates obstructive hydrocephalus. (B) T2 fluid-attenuated inversion recovery (FLAIR) MRI demonstrates large diencephalic mass. (C) T1-weighted sequence shows contrast enhancement of diencephalic lesion. (D) T2-FLAIR MRI demonstrates interval change with new hyperintensity within left medial temporal lobe. (E) Accompanying T1-weighted contrast enhancement of left medial temporal lobe. (F) T2-FLAIR MRI shows decreased T2 signal in the mesia temporal lobes following chemotherapy and high-dose prednisone. (G) Accompanying decrease in T1-weighted contrast enhancement of left medial temporal lobe. 


\section{Section 2}

Acute obstructive hydrocephalus is a medical emergency that can result in life-threatening neurologic injury if not promptly recognized and treated. It is an indicator of a CNS process obstructing the normal flow of CSF through the ventricular system, resulting in increased intracranial pressure (ICP). Headache is a common, nonspecific presenting symptom of increased ICP, often accompanied by additional alarming symptoms such as depressed level of consciousness, confusion, agitation, nausea, and vomiting. Headaches may be aggravated by maneuvers that increase ICP (such as coughing, sneezing, or straining), and patients may describe transient visual disturbances from pressureinduced ischemia of the optic nerve. ${ }^{1}$ Key examination findings may include decreased arousal, impaired upward gaze, cranial nerve 6 palsies, or posturing. Focal cranial nerve or motor signs are variably present and help localize the underlying disease process contributing to increased ICP. ${ }^{1}$

Diencephalic lesions can cause excessive daytime sleepiness and confusion, and therefore can mimic symptoms associated with increased ICP. However, diencephalic pathology is often accompanied by neuropsychiatric manifestations such as anxiety, depression, hallucinations, and memory loss. ${ }^{2}$ The differential diagnosis in this patient's case is broad and includes neoplasm, inflammatory process, autoimmune or paraneoplastic disorder, and infection.

\section{Question for consideration:}

1. What diagnostic evaluations could be considered for this patient?

GO TO SECTION 3 


\section{Section 3}

Our patient underwent numerous investigations: serologic tests included inflammatory markers (erythrocyte sedimentation rate, C-reactive protein, and antinuclear antibody), aquaporin-4 (AQP4) antibodies, myelin oligodendrocyte glycoprotein (MOG) antibodies, and infectious testing including HIV, tuberculosis, and syphilis screening, bacterial cultures, and fungal cultures; all results were normal. CSF analysis revealed the following: total nucleated cells (TNC), 12 cells/ $\mu \mathrm{L}$; erythrocytes, 1,000 cells $/ \mu \mathrm{L}$; protein, $98 \mathrm{mg} / \mathrm{dL}$; glucose, $69 \mathrm{mg} / \mathrm{dL}$; 0 oligoclonal bands; negative cytology and flow cytometry; negative bacterial and fungal testing. A CT chest/abdomen/ pelvis was unremarkable.

Both serum and CSF autoimmune encephalopathy panels were sent to Mayo Clinic, which includes antibodies directed against N-methyl-D-aspartate receptor (NMDAR), leucinerich glioma-inactivated 1 (LGI-1), contactin-associated protein 2 (CASPR2), glutamic acid decarboxylase (GAD65), GABA receptor, $\alpha$-amino-3-hydroxy-5-methyl-4-isoxazolepropionic acid (AMPA) receptor, antineuronal nuclear antibodies (ANNA-1, ANNA-2, ANNA-3), antiglial nuclear-1, Purkinje cell cytoplasmic antibody type 1 and type 2 (PCA-1, PCA-2), amphiphysin, and collapsin response-mediator protein-5 (CRMP-5); these panels were negative.

Without a clear diagnosis and remaining concern for neoplasm, a left hypothalamic biopsy was performed, which demonstrated inflammation with abundant macrophages and some demyelinating features. Although findings were nonspecific, the patient was treated for a presumed inflammatory etiology with IV methylprednisolone $1,000 \mathrm{mg}$ for 5 days, followed by prednisone $60 \mathrm{mg}$ daily. The patient showed improvement in alertness and communication with corticosteroids, and left the hospital ambulatory within days.

The patient's condition declined over the next 4 months despite a gradual taper from 60 to $50 \mathrm{mg}$ of prednisone. Symptoms included shaking spells (without EEG correlate), dysthermia, hypersomnolence, hyperphagia, hypothyroidism, and central diabetes insipidus. Due to clinical deterioration without a clear diagnosis, the patient was transferred to our facility for further evaluation. An MRI of the brain was repeated and revealed a reduction in the size and degree of enhancement of the diencephalic lesion, but there was new T2 hyperintensity and gadolinium enhancement in the left medial temporal lobe (figure, $\mathrm{D}$ and $\mathrm{E}$ ). Repeat lumbar puncture revealed the following: TNC, 26 cells $/ \mu \mathrm{L}$ (95\% lymphocytes); protein, $218 \mathrm{mg} / \mathrm{dL}$; glucose, $50 \mathrm{mg} / \mathrm{dL}$; 0 oligoclonal bands; and negative cytology and flow cytometry.

Our patient is a young man with a partially steroid responsive diencephalic brain lesion and new imaging findings of temporal lobe enhancement. An autoimmune or paraneoplastic etiology was strongly suspected at this point. A review of the differential diagnosis of limbic encephalitis is included (table e-1, links.lww.com/WNL/A388).

\section{Questions for consideration:}

1. What additional studies are warranted in this patient?

2. What are the diagnostic considerations in a patient who presents with limbic encephalitis?

\section{GO TO SECTION 4}




\section{Section 4}

Limbic encephalitis is often an autoimmune or paraneoplastic phenomenon and it should prompt thorough evaluation for a causal antibody and underlying malignancy. In patients with a suspected paraneoplastic disorder, PET-CT is $20 \%$ more sensitive than standard body CT in identifying an underlying malignancy, and over 50\% more sensitive in patients with classic paraneoplastic autoantibodies. ${ }^{3}$ Testicular or pelvic ultrasounds should also be considered due to the poor sensitivity of PET in detecting pelvic pathology. In young male patients with diencephalic and medial temporal lobe contrast enhancement, strong consideration should be given to the possible presence of $\mathrm{Ma}-1$ and $\mathrm{Ma}-2$ antibodies and a testicular germ cell tumor. ${ }^{4,5}$ Therefore, our patient subsequently underwent a testicular ultrasound, PET-CT scan, and serologic testing for Ma-1 and Ma-2 antibodies. Testicular ultrasound was unrevealing, but PET-CT scan revealed a hypermetabolic $4 \times 2 \mathrm{~cm}$ lobulated soft tissue mass within the anterior mediastinum. A CT-guided biopsy was performed, revealing a syncytiotrophoblast-rich malignancy with extensive necrosis, consistent with a germ cell tumor. Serologic testing for Ma-2 antibodies returned positive shortly after the pathology results returned.

Our patient was diagnosed with anti-Ma-2-associated encephalitis in the setting of a mediastinal germ cell tumor. He was continued on prednisone and initiated on chemotherapy with cisplatin, etoposide, and bleomycin. His hypersomnolence was treated with modafinil and he transferred to inpatient rehabilitation. He received an additional course of IV steroids followed by prolonged high-dose oral corticosteroids during chemotherapy. Cyclophosphamide was also considered to treat what is likely a T-cell-mediated inflammatory process, but was ultimately deferred due to unfavorable side effect profile with concurrent chemotherapy and poor hydration status. Three months later, the patient has experienced moderate clinical improvement with marked radiologic improvement (figure, F and G); severe residual hypersomnolence remained.

\section{Discussion}

To our knowledge, this is the first case of anti-Ma-2associated encephalitis leading to obstructive hydrocephalus. Anti-Ma-2-associated encephalitis has a particular affinity for the diencephalon, limbic system, and brainstem. Symptoms include many of the cardinal features of a diencephalic syndrome: brainstem and limbic encephalitis, accompanying amnesia, seizures, excessive daytime sleepiness, dysthermia, pituitary hormonal dysfunction, eye movement abnormalities, and psychiatric symptoms are common. ${ }^{2,4,6}$ While headache is not a common presenting symptom in anti-Ma-2-associated encephalitis, new-onset headache has been associated with autoimmune encephalitis, particularly in patients with anti-NMDAR encephalitis. ${ }^{7}$ Most patients with anti-Ma-2-associated encephalitis have T2hyperintense signal in the diencephalon, medial temporal lobes, or brainstem in varying combinations and severity, with a significant proportion demonstrating avid contrast enhancement, which is unlike most other examples of autoimmune encephalitis. ${ }^{4,6}$

Anti-Ma-2-associated encephalitis is most common in younger male patients with testicular germ cell tumorsrepresenting over half of patients with this syndrome-but can also occur in women and in older patients with nonsmall-cell lung carcinoma, breast cancer, and other tumors. ${ }^{2,4,6}$ Treatment includes management of the underlying malignancy with surgery, chemotherapy, and radiation, often with coinciding immunotherapy. Despite aggressive cancer treatment and immunotherapy, the prognosis is often poor, as only one-third of patients have been reported to experience neurologic improvement while half continue to deteriorate. ${ }^{4}$ Long-term outcome data are limited though, suggesting that aggressive cancer treatment and immunotherapy are reasonable to achieve the best possible clinical outcome.

This case highlights some of the inherent challenges in the evaluation of encephalitis, but careful diagnostic evaluation despite a nondiagnostic brain biopsy is still critically important and can lead to a definitive diagnosis. Physicians should have a low threshold to screen for anti-Ma-1/Ma-2 antibodies and germ cell tumors in suspected autoimmune or paraneoplastic encephalitis, particularly in young male patients. PET-CT and testicular or pelvic ultrasound increase the sensitivity of detecting an underlying malignancy and should not be delayed if a paraneoplastic etiology is suspected. In this particular example, anti-Ma-2-associated encephalitis was clinically suspected and subsequently confirmed in a young man with typical clinical features, albeit with atypical neuroimaging features.

\section{Author contributions}

Stephen W. English: case selection, research, and manuscript writing. B. Mark Keegan: critical revision of manuscript. Eoin P. Flanagan: critical revision of manuscript. W. Oliver Tobin: critical revision of manuscript. Nicholas L. Zalewski: case selection, manuscript writing, critical revision of manuscript.

\section{Study funding}

No targeted funding reported.

\section{Disclosure}

S. English reports no disclosures relevant to the manuscript. M. Keegan receives publishing royalties for Common Pitfalls in Multiple Sclerosis and CNS Demyelinating Diseases. E. Flanagan, W. Tobin, and N. Zalewski report no disclosures 
relevant to the manuscript. Go to Neurology.org/ $\mathrm{N}$ for full disclosures.

\section{References}

1. Wijdicks E. Acute Obstructive Hydrocephalus: The Practice of Emergency and Critical Care Neurology. 2nd ed. New York: Oxford University Press; 2016:532-541.

2. Anderson NE, Barber PA. Limbic encephalitis: a review. J Clin Neurosci 2008;15:961-971.

3. McKeon A, Apiwattanakul M, Lachance DH, et al. Positron emission tomographycomputed tomography in paraneoplastic neurologic disorders: systematic analysis and review. Arch Neurol 2010;67:322-329.
4. Dalmau J, Graus F, Villarejo A, et al. Clinical analysis of anti-Ma2-associated encephalitis. Brain 2004;127:1831-1844.

5. Dalmau J, Bataller L. Clinical and immunological diversity of limbic encephalitis: a model for paraneoplastic neurologic disorders. Hematol Oncol Clin North Am 2006;20:1319-1335.

6. da Rocha AJ, Nunes RH, Maia AC Jr, do Amaral LL. Recognizing autoimmunemediated encephalitis in the differential diagnosis of limbic disorders. AJNR Am J Neuroradiol 2015;36:2196-2205.

7. Schankin CJ, Kastele F, Gerdes LA, et al. New-onset headache in patients with autoimmune encephalitis is associated with anti-NMDA-receptor antibodies. Headache 2016;56:995-1003. 


\section{Neurology}

Clinical Reasoning: A 30-year-old man with headache and sleep disturbance

Stephen W. English, B. Mark Keegan, Eoin P. Flanagan, et al.

Neurology 2018;90; 1535 -e 1540

DOI 10.1212/WNL.0000000000005356

\section{This information is current as of April 23, 2018}

Updated Information \&
Services

References

Subspecialty Collections

Permissions \& Licensing

Reprints including high resolution figures, can be found at: http://n.neurology.org/content/90/17/e1535.full

This article cites 6 articles, 1 of which you can access for free at: http://n.neurology.org/content/90/17/e1535.full\#ref-list-1

This article, along with others on similar topics, appears in the following collection(s):

Autoimmune diseases

http://n.neurology.org/cgi/collection/autoimmune_diseases Hydrocephalus

http://n.neurology.org/cgi/collection/hydrocephalus

Paraneoplastic syndrome

http://n.neurology.org/cgi/collection/paraneoplastic_syndrome

Information about reproducing this article in parts (figures,tables) or in its entirety can be found online at:

http://www.neurology.org/about/about_the_journal\#permissions

Information about ordering reprints can be found online:

http://n.neurology.org/subscribers/advertise

Neurology ${ }^{\circledR}$ is the official journal of the American Academy of Neurology. Published continuously since 1951, it is now a weekly with 48 issues per year. Copyright (C) 2018 American Academy of Neurology. All rights reserved. Print ISSN: 0028-3878. Online ISSN: 1526-632X.

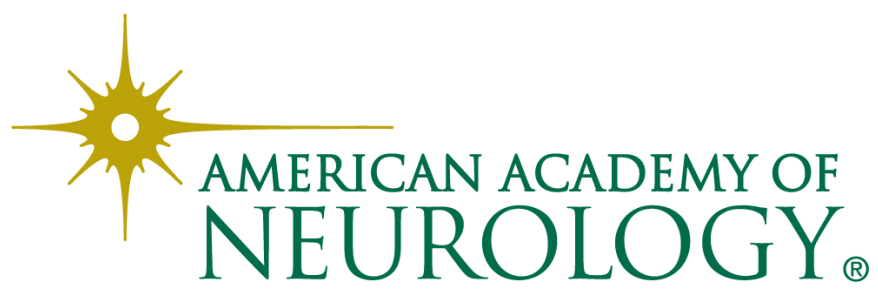

